\title{
Africa in the globalising world: digital divide or human divide?
}

\section{CS de Beer}

\author{
Abstract \\ This paper describes the situation of a humanised future for Africa, against all the \\ negative commentaries regarding the continent, and against all forms of \\ dehumanisation, which would mean a situation of drastic humanisation. This \\ implies the description of an ethical responsibility for the creation and invention of \\ a future of hope. The assumption is that knowledge is the key issue here that can \\ guarantee a future of hope and wellbeing. Knowledge should be the main focus \\ and not poverty relief, the search for identity, or the information and \\ communication technology explosion. For this reason the digital divide is posed \\ as a highly questionable term; it is much rather a human divide than a digital \\ divide. Not technics, but humans pose the problem. For this very reason humans \\ should solve the problem. Humans are in possession of a unique capacity, a \\ universally distributed intelligence, by means of which the problem of a divide \\ can be solved. For a future of hope to emerge, human abilities and qualities \\ should be mobilised in terms of noological dynamics, rather than in terms of \\ technical devices.
}

Keywords: ethical respnsibility, knowledge, human divide, noological dynamics. mondialisation

\section{INTRODUCTION: THE CONTEMPORARY STATUS OF AFRICA}

Contemporary Africa: in search of identity in a global world (cf. Castells (1997) on 'the power of identity'); in search of information in an age of information explosion (Dupuy 1980); in search of poverty relief (while each one can plant his own cherry tree - Lenoir 1984)) in the midst of extreme wealth and affluence in other parts of the world.

We have to accept, I think, that these three issues are interconnected and interdependent.

Many accusations have been levelled against Africa; many diagnoses have been made of the state of Africa; many solutions to problems have been suggested. It cannot be denied that Africa, generally speaking, is in deep crisis. We may be so dumbed down that we cannot contemplate any improvements in our own civic intelligence, which is precisely the opposite of what this presentation hopes to achieve. Paolo Freire, in his Pedagogy of hope (1992) warns against such an experience of hopelessness: 'When it becomes a program, hopelessness paralyses us, immobilizes us. We succumb to fatalism, and then 
it becomes impossible to muster the strength we absolutely need for a fierce struggle that will recreate the world.'

On this note a position of hope is advocated, not in the utopian sense but in a very realistic sense. One thing is certain, although not generally accepted: inaccurate, piecemeal identifications and descriptions of problems will inevitably lead to inadequate and even inappropriate answers, strategies, and solutions. One such example I wish to focus on in order to illustrate this point is the socalled problem of 'the digital divide'. We must try to put the finger right on the spot of the crisis.

It has to be accepted that Africa forms part of a global and globalising world. This process of globalisation has its own demands, rhetoric and challenges, and it is important to grasp these processes as accurately as possible, but also to realise that no one can be prescriptive about the directions these developments have to take, or should take. Unfortunately the human world is so extremely complex that it is almost impossible to reach clear understandings of situations. For that reason it is important to share as many views and insights as possible in the process. A clear view should be developed of exactly what information and communication technologies - in terms of real and virtual realities and spaces are able to offer and how important they are for comprehensive and adequate solutions (with the realisation, of course, that the process of globalisation is directly linked to these technical developments). ICTs are central in this: real and virtual realities and spaces. It would be important to develop a clear view on the limitations - they are not replacements for humans, and neither are they infallible.

Right at the start it would be wise to take heed of the important suggestion made by Derrida, who prefers the French term mondialisation (worldisation) to globalisation since the word introduces and emphasises the human factor so strongly. What exactly does this imply for Derrida, compared to globalisation? $\mathrm{He}$ writes:

Today the renewed and re-elaborated declaration of "human rights" (1948) ... and the institution of the juridical concept of "crime against humanity" (1945) form the horizon of mondialisation and of the international law that is supposed to keep watch over it. The concept of man, of what is proper to man, of human rights, of crimes against the humanity of man organises, as we know, such a mondialisation or worldwide-ization. This mondialisation wishes to be a humanization (Derrida 2002: 203).

(I have retained the French word mondialisation in preference to 'globalization' or globalisierung, so as to maintain a reference to the world - monde, Welt, mundus - which is neither the globe nor the cosmos.) 
It refers to the creation of a human world. Where there are poverty-stricken people, there is no human world - it is a place of suffering. Where extreme poverty is encountered, especially amidst extreme wealth, there we find a deep human contradiction, an antihuman world or a dehumanised world. This research note seeks to describe a situation of drastic humanisation, to describe an ethical responsibility for the creation of a future of hope, since only a future of hope can possibly mean a humanised future.

\section{A FUTURE OF HOPE}

In an effort to comply with the orientation suggested above, I wish to start on a very positive note with a quotation from Pierre Lévy (1997: 1-2) which sketches some kind of future of hope for Africa - at least that is how I wish to interpret this paragraph:

The prosperity of a nation, geographical region, business, or individual depends on their ability to navigate the knowledge space. Power is now conferred through the optimal management of knowledge, whether it involves technology, science, communication, or our "ethical" relationship with the other. The more we are able to form intelligent communities, as open-minded, cognitive subjects capable of initiative, imagination, and rapid response, the more we will be able to ensure our success in a highly competitive environment. Our material relationship to the world is maintained through a formidable epistemological infrastructure: educational and training institutions, communications networks, digitally supported intellectual technologies, the continuous improvement and distribution of skills. In the long term everything is based on the flexibility and vitality of our networks of knowledge production, transaction, and exchange.

Knowledge seems to be the key issue here that guarantees a future of hope and wellbeing. Knowledge should become our main focus and not poverty relief, not identity searches, and not the information explosion. Not that these issues are not very important, but they depend on our disposition towards knowledge. Navigating the knowledge space, managing this knowledge, producing and exchanging knowledge, in other words making it available around us by creating intelligent (i.e. knowledge) communities and utilising, developing and refining existing knowledge infrastructures are the routes or avenues to be explored towards a future filled with hope; a future to be recommended to our children. On these avenues we will discover who we are or want to be, what the real solutions to the problems of poverty might be, and how information as knowledge for action can be activated. A knowledge culture should be created. 
People are in possession of the required abilities. We are able to navigate knowledge spaces, we are able to organise knowledge as it relates to technical developments and scientific investigations, communicating it to others. By simply telling what we know, we are able to relate responsibly, ethically, to the other; we can establish with ease intelligent communities within the knowledge infrastructures we have. All this can be done because of the universally distributed intelligence we all share with one another. We can be open-minded if we want to be because we are cognitive subjects capable of initiatives, imagination and enthusiasm. We are intelligent beings, capable of all these things, but we have to make our intelligence work for us and we have to work with it. It requires a deliberate, committed focus - a primary place on the agenda.

\section{DIGITAL DIVIDE - A QUESTIONABLE TERM?}

\section{Assumptions}

Against this background it becomes, to my mind, highly contestable to problematise the African situation, for example, in terms of the so-called 'digital divide'. The digital divide focuses on information rich and information poor, on the divide in other words. But focusing on the divide creates the idea of opposition; it polarises rather than reconciling or bringing together the two sides of the divide. Such a metaphor creates a simplified picture of the real problems - as if some know and others do not know, with the implication that some are able and some are not. And, those who know also know the solutions because how can those who do not know have any knowledge of solutions? The solutions offered may benefit those who know and not necessarily those who do not know. (See also Lievrouw and Farb 2002 for the disadvantages of these terms.) On the other hand it also creates the understanding that it is due to a capitalist ploy that some people are exploited for the enrichment of others. Another dangerous assumption is that the divide has to do with electronic media, that it is a divide between those with access and those without access to information via computers and the Internet. This viewpoint does not take into account intrapolar divides, in other words the divides existing within information-rich and information-poor societies.

We must also give a historical sense to the issue: long before the digital divide rhetoric (with its predominant focus on information) and information and communication technologies existed, there were people and nations who knew and those who did not know, or rather some peoples 'knew' differently from others. Some were rich and others were poor. The impressive cultural creations - over centuries - in so many parts of the world without access to digital means, confirm this point.

\section{A dangerous metaphor}

'Digital divide' sounds impressive and is somehow very descriptive of the situation at issue here: there is a divide between information rich and information 
poor. At the same time it can be highly ambiguous because the boundaries are not exactly clear. The metaphor is a double-edged sword; it cuts both ways, i.e. the situation is very serious, being inherent to rich as well as poor societies. Such metaphors can sometimes invite easy ideological posturing. Similar simplifications equally easily obscure possible solutions to the identified problem. The deeply justified concern is poverty, both informational and by implication economic - the one affects the other, and somehow their impact is mutual. Although this may be true, the way in which these views are articulated requires that we tackle the issue responsibly and not in terms of simplicities, personal preferences or a lack of differentiation between what is of primary and what of secondary importance.

The notion of a divide creates oppositions and is inclined to deepen those rifts, rather than overcome them, especially because those on the winning side set the conditions. It also limits the divide to technical haves and have nots, and selfevidently the solutions to the divide are then to equip the have nots with what the haves produce. This divide is digital, merely digital; it is a technical electronic divide - the emphasis is not on the humanness of the divide. Who will benefit? The real issue is not identified. Those with equipment have access and the rest do not; in order to get access, equipment is required. What to do with what becomes accessible also poses a problem. The divide can only be narrowed by accessing the accessible - something which is not self-evident. Other abilities are required, like understanding, interpretation and insight in order to achieve access in the real sense of the word, but this is hardly addressed in efforts to solve the problem. The assumption is that access is good; as if it stands to reason that everybody wants access or even needs access, and knows what to do with what is accessible.

\section{Passion for ignorance}

But what about the will to ignorance, or even the passion for ignorance as emphasised by psychoanalysis (cf. Felman 1987). How to deal with this real human issue is not addressed in the studies I am aware of. What is important is not only the capacity and ability to make something out of accessed information, but especially the willingness and keenness to know and understand. Personally I am convinced that the real problem lies here. Poverty relief requires knowledge, but knowledge is very often hindered in many ways: through ideological strategies or policies that prescribe the kind of knowledge needed; educational approaches that are deterrents to knowledge and its full development; information and communication technologies that put non-technical (especially human inputs and endeavours) under suspicion; and many others. These different obstacles to knowledge may best be summarised when they are seen as converging in what some psychoanalysts would call 'the lively will to ignorance' or even 'a passion for ignorance' as a deep, unconscious drive. This passion for ignorance is heavily present inside and outside the boundaries of the gaps and divides. It poses such a serious threat that a thinker of the stature of 
George Steiner refers to 'the barbarism of ignorance' (Steiner 1999). It is our challenge and responsibility to reverse this situation, but we will come back to it later.

\section{Different knowledges}

Sometimes this divide or 'gap' is referred to as a 'knowledge gap', especially in view of a conception of knowledge that considers other conceptions of knowledge as inferior, and the own as superior. This is not a new problem that has emerged with the advent of the computer age, and for that reason computers may also not be the sole or final solution to these so-called 'gaps' (or 'divides' for that matter). This should be investigated in all its complexities and nuances which includes the tricky relationship between knowledge and information. It may be a matter of the gap between different forms of knowledge. The phenomenon of 'different knowledges' is therefore important here and should be attended to in order for connections between these knowledges to be established in a significant way. It would also be important to appreciate and articulate knowledge in its full complexity as an extremely dynamic entity, since the reasons for identifying gaps may relate specifically to this concept, which does not have a lot to do with digital divides.

According to many, in very simplistic terms the 'divide' is due to a capitalist plot, a process in which people are exploited by many for their own benefit. On the other hand, it may be exploitative, but it is not without significant usefulness as well. Contemporary Africa is trapped in the claws of that giant god, The Market, which directs everything. As stated in a recent SABC news programme: 'The Market has taken; the Market has given.' It remains important to find ways to channel benefits in a more balanced way than is currently the case. It seems that even this accusation has different sides to it, which calls for careful analysis. There are many assumptions of this nature that are (or may be) dangerous or deceptive. Most of the time they are ideologically motivated and as such have an extremely distortive function. Some of these weakly identified and analysed assumptions are: capitalism is evil; machine intelligence is superb and excels; ubuntu will nevertheless solve all problems; what is Western is evil; the denial of evil despite its monstrous manifestations; sweeping statements about being black and being white contribute nothing, but manage rather to create prejudices that promise eventual unavoidable disaster; etc. Strategies that emerge out of these and other assumptions are all (because of the ideological distortions related to them, and which lie at their roots) self-defeating.

\section{Access and needs}

Against this background access and the use of computers and information do not offer solutions in any self-evident way or straightforward manner. Access in itself will not solve anything. What should be done with what is accessible? Once availability and accessibility have been sorted out, what is available should be 
treated in a specific way. Readership, interpretation, understanding, evaluation and other matters need to be attended to in this context. Levels of literacy should be raised if knowledge is such a decisively important issue. Human capacity to access does not merely imply physical, mechanical and even economic abilities but also an intellectual willingness or proneness, a keenness to know.

Identifying a divide, assumes that there is a need. But is there really a need, and what is its scope? To what extent do people indeed experience a need, or are others keen to create a need for whatever reason? A needs analysis is called for since needs, apart from emerging in a spontaneous and natural way, can be artificially or ideologically created (Baudrillard 1981) for the sake of doing good business or driving a successful political campaign, for example. Or to enjoy what others enjoyed before, simply because they found it enjoyable (albeit something highly necessary). In other words, as Lievrouw and Farb (2002: 529) put it, we have to determine what people, individuals and communities really value doing and having, and what they really want to be. Insight into these very fundamental values will qualify the need to be fulfilled and the type of 'transfer' of means for solutions required in each case. But even this process of transfer is highly complex, as shown by Serres (1977) and Debray (2000). Work needs to be done on this if we want to proceed in a hopeful manner.

\section{WHAT WOULD BE THE DIRECTION TO A FUTURE OF HOPE?}

Perhaps enough research has been done on what is generally referred to - and with good reason - as the 'divide'. Perhaps it is an artificial problem, like the question of artificial intelligence. In the sense that artificial intelligence rests on the assumption that there is some other kind of intelligence, apart from human intelligence, we may also accept that the digital divide rests on another kind of divide, namely a human divide. If it is a human divide it may be solved not by technical means and devices, but by mobilising human abilities and qualities.

Where to start? We could begin by ignoring the divide and starting to work on what is not divided, namely the universally distributed intelligence, the universal ability to know and apply this knowledge to our benefit. We are in possession of the equipment; we do not need to buy it, but simply have to start using it. With reference to this equipment, Gregory Ulmer (2003: 6) writes: 'The one negentropic force in the world is human intelligence (creativity): we should consider this moment [in history] as a time for invention.'

Whoever embraces this insight, understanding or knowledge of what it means to be human will have no reason to be despondent, but will have cause for celebration - to celebrate the future of hope, the future to be invented if we apply our minds, intelligences and means in as far as these are available to us. Forget about blame, exploitation and all kinds of negativities which sap our energy and extinguish all enthusiasm. 
There is hope, indeed, but on condition that the real human capacity is fully utilised. It must be considered of primary importance versus other resources that are and can only be supportive and complementary (although not at all unimportant).

\section{Our unique human capacity}

The utilisation of human capacity can be done by the given abilities referred to as the noological dynamics (the neglected and currently underrated or even unmentioned dimension of human ability, which carries within itself the guarantee that when applied the world will change, coming from the Greek word nous, meaning spirit or mind). Edgar Morin (1991), in a very fine publication on ideas, uses the terms noosphere (as the life or domain of human ideas) and noology (the dynamic organisation and application of ideas) to describe noological dynamics. This is a description of the anthropos, the human being, in universally valid terms. The issue may be differently articulated in different languages and by different cultures, but the nature of this special ability remains the same. Humans are, in other words, uniquely equipped with the very sophisticated 'raw material'. Utilising it optimally is the challenge that confront us. The continuous drift of the human world, so well described by Pierre Lévy (1997: 245-255), is the expression of this special capacity of intelligence or nous, and it manages to take societies forward in the direction of a future of hope. We therefore need a revival of human intelligence, despite forgetfulness about its deepest and most dynamic nature and despite the fact that we are stupefied by more convincing, easy sounding but less effective and rewarding alternatives, called 'skills'.

The notion of a digital divide is born from an overemphasis on machine intelligence and the related marvels of ICTs, while ignoring the human factor which manifests as human intelligence or inventiveness (that ever-present factor, even on days when ICTs were still lacking in their contemporary dynamic!). Let us never forget what humans managed to achieve worldwide before the introduction and impact of these techniques. They are certainly reinforcing the noosphere and making it much more dramatic than it used to be, but they most certainly are not the creators of this human sphere of intelligence - much rather a kind of manifestation of this ability.

Apart from the universally distributed intelligence by which we are all equipped in a distinct way, it also belongs in an etymological sense to the term 'intelligence' to be able to establish relationships and connections - literally the ability to read between the lines. It is a natural given. That is why the term 'collective intelligence' features in this context in such a prominent way, and why the establishment of intelligent communities on this basis is equally important. 


\section{Mobilising this human capacity}

The acceptance of the notion of collective intelligence implies the acceptance in principle of a bridge across the divide. For this reason, let us forget about the divide. It has a sterilising and paralysing function. Let us organise our focus on intelligence, on collective intelligence and on the clearly implied establishment of intelligent communities. The main focus should be on human ability - noological ability - and its cultivation. This is exactly the point where Derrida's notion of mondialisation or worldisation (or worldwide-isation, as it is translated) becomes a central issue. Intelligent communities mean the creation of a special human world in which the most unique ability of humans is given the opportunity to excel. Intelligent communities are human communities, not computer laboratories.

Knowledge and intelligence are our biggest assets in the creation of wealth, both spiritual and financial. The possibilities should be explored to the ultimate. The notions of $\mathrm{Cl}$ and $\mathrm{IC}$, rather than ICT, offer a promising opening to a new, future world of hope, although information and communication technologies are valuable supportive resources.

It is based on the assumption that all of us have intelligence, and not a single individual is excluded; the cultivation and pooling of these intelligences create piles of intellectual wealth and richness in all domains, where required. From these sources of wealth the inevitable outcome will be human well-being. That will at least include proper and sufficient food, shelter and health care.

What to do in practice, with this task of mobilisation?

Some fundamental guidelines for serious consideration are offered very briefly:

- Create clusters of contagious intelligences instead of focusing only on individual intelligences. The expansion of these communities should be a matter of great priority: creating a taste for knowledge and an ability to celebrate insight - 'Give us our daily hunger' somebody once wrote in this regard. This is to reverse the will to ignorance and the threat of barbarism.

- Whose initiative? Collective initiatives involving all, irrespective of race, age, level of literacy or culture, must be initiated. Utilise the available means to achieve this.

- Reconfigure institutions in terms of the complex dynamics of the situations we are dealing with. Institutions should accommodate human intelligence, as described earlier, and cultivate and refine these capacities if they wish to contribute to the invention of a future for Africa. It will not come as a surprise, nor will it happen unexpectedly. It must be worked for with all available qualities or abilities, and with enthusiasm. Concerted efforts to depoliticise and revitalise, reinforce and re-inspire communities will bring 
back human strength and dynamics and make the institutions and intelligent communities work at full pace.

- The nature of education and training of information professionals, with a view to the noological dynamics, the realisation of collective intelligence and the construction of intelligent communities, should become a matter of priority. In short: knowledge and information workers should focus on the art of and commitment to inventiveness, and must be able to display some sensitivity towards humans and collectives. Only when the spirit of invention is revitalised will the dynamics of appropriate techniques be able to play a superb role. It would be useful to take note of an important article by Mason (1990) on information professionals and what their focus should be.

- The idea of a universally distributed intelligence (UDI), as mentioned before, must be taken as point of departure and constantly brought to the attention of whoever decides to collaborate in these processes.

- The emergence and turbulence of human reality should always be kept in mind. Human reality is an amazing phenomenon; it varies through history from the extremes of orderliness, to extremes of messiness. In the process there are many sufferers and beneficiaries. It remains a constant threat to us all, but also a constant promise of the future of hope which we are contemplating. This 'great ontological and noetic machine' as Pierre Lévy (1997) calls it, should never be allowed to escape our attention and focus. That is what guarantees our survival.

- The human value of technical developments should be considered as being of primary importance in this context, and not the value of technical developments per se.

- Decolonisation must not lead to re-colonisation in other terms. What this means is that we should get rid of any eagerness to possess, control, manipulate and take hold of. The intelligent community is meant to be a free community which takes full responsibility for every member, the human race in general and for a meaningful future for all.

- A critical epistemic analysis of all kinds or forms of knowledges, in terms of archaeology, genealogy and deconstruction would be required for responsible action in an intelligent community ... a critical means aimed rather at embracing and appreciating, than selecting, choosing and rejecting. It is much rather a matter of understanding than of evaluation. These knowledges should be refined, reworked and regenerated into information for action (Kuhlen 2004). If information does not easily lead to some kind of action, it is sterile and fruitless.

- Reconceptualising the digital divide into terms like social inclusion (Warschauer 2002), and information equity (Lievrouw and Farb 2002) is what remains. People in this context will simply refuse to participate in promoting the idea of a divide.

- We must realise timeously that complex problems - and the issues dealt with here - are all of a very complex nature which can never be solved by simplistic (or simplified) solutions. 'The simple is always the simplified', 
said that great chemist and philosopher of science, Gaston Bachelard. It is dangerous for a future of hope to believe that simplifications will make the road to this future easy and smooth.

\section{CONCLUSION}

I wish to close with the following four statements borrowed from the inspirational book by Pierre Lévy, in slightly adapted form (1997):

The prosperity of the African continent and our own region depends on the ability to navigate knowledge space. Refusal to do so will end in disaster.

Everything is based on the flexibility and vitality of our networks of knowledge production, transaction, and exchange. These networks should be cultivated to involve as many individuals and groups as possible, in the processes of production and exchange.

The relatively sudden downfall of Communist governments was due to their incapacity to pursue collective intelligence, because of the crisis of social and cultural integration.

This integration is a non-negotiable condition in the globalising world of survival and the search for prosperity. All intelligences are valuable and vital for building a future of hope.

The ability to form intelligent communities will become the decisive weapon in the competition for globalised intellectual and economic space. The initiative of forming such communities should be taken without delay, since it will provide the space for the invention of futures that matter.

Let this be our task for achieving a future of hope: the firm rejection of a mood of hopelessness (Freire 2004) and let us be equally determined in embracing the imperative of responsibility (Jonas 1984).

\section{REFERENCES}

Albaret, I. (ed). 1997. Savoir échanger les savoirs. Paris: Textuel.

Baudrillard, J. 1981. The ideological genesis of needs. In For a critique of the political economy of the sign. St Louis (MO): Telos Press.

Britz, J.J. 2004. To know or not to know: a moral reflection on information poverty. Journal of Information Science 30(3): 192-204.

Castells, M. 1997. The power of identity. Oxford: Blackwell Publishers. 
Debray, R. 2000. Transmitting culture. New York: Columbia University Press.

Derrida, J. 2002. Without alibi. Stanford: Stanford University Press.

Dupuy, J-P. 1980. Myths of the informational society. The myths of information: technology and post-industrial culture. K. Woodward (ed). London: Routledge.

Feenstra, A. and D. Barney. 2004. Community in the digital age: philosophy and practice. Lanham: Rowman \& Littlefield Publishers, Inc.

Felman, S. 1987. Jacques Lacan and the adventure of insight. Cambridge (Ma): Harvard University Press.

Freire, P. 2004. Pedagogy of hope. New York: Continuum.

Haywood, T. 1995. Info-rich - Info-poor: access and exchange in the global information society. London: Bowker/Saur.

Jonas, H. 1984. The imperative of responsibility: in search of an ethics for the technological age. Chicago: The University of Chicago Press.

Kuhlen, R. 2004. Informationsethik. Konstanz: UVK Verlagsgesellschaft.

Lévy, P. 1997. Collective intelligence: mankind's emerging world in cyberspace. New York: Plenum Trade.

Lievrouw, L.A. and S.E. Farb. 2002. Information and equity. Annual review of information science and technology 36: 499-540.

Mason, R.O. 1990. What is an information professional? Journal of Education for Library and Information Science 31(2): 122-138.

Morin, E. 1991. La méthode. Numero 4. Les idées: leur habitat, leur vie, leurs moeurs, leur organisation. Paris: Seuil.

Serres, M. 1977. Hermes IV: la distribution. Paris: Minuit.

Steiner, G. 1999. La barbarie de l'ignorance. La Tour d'Aigues: Editions de l'Aube.

Ulmer, G. 2003. Internet invention: from literacy to electracy. New York: Longman.

Warschauer, M. 2002. Reconceptualizing the digital divide. Available online: www.fistmonday.dk/issues/issue7_7/warschauer/index.html. (Accessed on 200307-18.) 